\title{
Soft Tissue Reconstruction around the Ankle with Sural Artery Flap \\ MA CHOWDHURY ${ }^{\mathrm{a}}$, SH KHUNDKAR ${ }^{\mathrm{b}}$, MAALI $^{\mathrm{C}}$, MO ISLAM $^{\mathrm{d}}$
}

\begin{abstract}
Summary:
Reconstruction for injuries around the ankle becomes a challenge due to limitation of available similar or near similar tissue. Tendons, bones and joints are frequently exposed after trauma because of the thinness of the subcutaneous tissue around the ankle. A durable flap with good texture, reliable vascularity, good arc of rotation and minimum donor site morbidity is always desired for coverage of such defect. Traditionally local flaps are used for resurfacing but their use is limited by their size and arc of rotation.
\end{abstract}

This study was done in the dept. of Plastic Surgery, NITOR from Dec, 2012 to Feb, 2016. Total number of patients was 50 and their age varied from 7 years to 55 years. Among

\section{Introduction:}

Coverage of soft tissue defects in the lower limb is a common procedure due to increase incidence of trauma. ${ }^{1}$ The loss of soft tissue around the ankle is a difficult problem to solve. Tendons, bones, joints are frequently exposed after trauma because of thinness of subcutaneous tissue around the ankle. ${ }^{2}$ Reconstruction for injuries around the ankle becomes a challenge due to limitation of available similar or near similar tissue. A durable flap with good texture, reliable vascularity, good arc of rotation, ease of dissection and minimum donor site morbidity is the most desired option for coverage of such defects. ${ }^{3}$

Skin graftings are unable to address problems of such complexity and healing by secondary intention usually leads to contracture and unstable scar. Traditionally

a. Dr. Maruf Alam Chowdhury, Assisant Professor, Department of Plastic Surgery, NITOR, Dhaka

b. Prof. Shafquat Hussain Khundkar, Honorary Professor, Popular Medical College and Hospital, Dhaka

c. Prof. Dr. Md. Ayub Ali, Head of the Department, Department of Plastic Surgery, NITOR, Dhaka

d. Dr. Md. Obaidul Islam, Registrar, Department of Plastic Surgery, NITOR, Dhaka.

Address of Correspondence: Dr. MarufAlam Chowdhury, Assisant Professor, Department of Plastic Surgery, NITOR, Dhaka. E-mail: maruf.alam.chowdhury@gmail.com

Received: 13 Nov. 2017

Accepted: 5 April 2018 the 50 patients, 41 patients recovered uneventfully, 8 patients showed partial flap necrosis and complete flap necrosis in 1 patient.

The distally based sural flap is a versatile and reliable flap for coverage of soft tissue defects around the ankle. Most of the cases were single stage procedure except extended reverse sural flap. The dissection is easy with short operative time and minimum morbidity. Thus the superficial sural artery flap can be used as a good alternative to microsurgical reconstruction.

Key words: Sural artery flap, wound around ankle, soft tissue reconstruction.

(J Bangladesh Coll Phys Surg 2018; 36: 101-106)

DOI: http://dx.doi.org/10.3329/jbcps.v36i3.37032

local flaps are used for resurfacing but their use is limited by their size and arc of rotation. Reverse flow flaps such as anterior tibial artery flap and posterior tibial artery flap require the sacrifice of major arteries. $^{2}$ Cross leg flap may be an extreme end of the options where no other option is available and free flap is not feasible.

The reverse flow sural artery flap does not require the sacrifice of major artery and can be used in lower limbs with arterial injury as long as peroneal artery is preserved. It may be performed as a single stage procedure with regional anaesthesia to enable early coverage of the defect. ${ }^{4}$ The advantage of the reverse flow sural artery flap is constant vascular anatomy, a large arc of rotation, preservation of major nerves and arteries and relatively fast, easy and reliable procedure. $^{4}$

The major disadvantage of the flap is the sacrification of the sural nerve leading to anaesthesia of an area of the lateral foot. This sacrifice produces minimum morbidity. This procedure provides a reliable alternative to other major reconstructive procedure even in patients with vascular risk factor.

Patients and Methods:

This was a descriptive longitudinal study carried out on 50 patients with wounds around the ankle between 
the time January 2012 to December 2016 in the department of plastic surgery, National Institute of Traumatology and Orthopedic Rehabilitation (NITOR), Sher-E-Bangla Nagar, Dhaka. Patients with major vascular trauma, diabetes mellitus, psychiatric illness were excluded from the study.

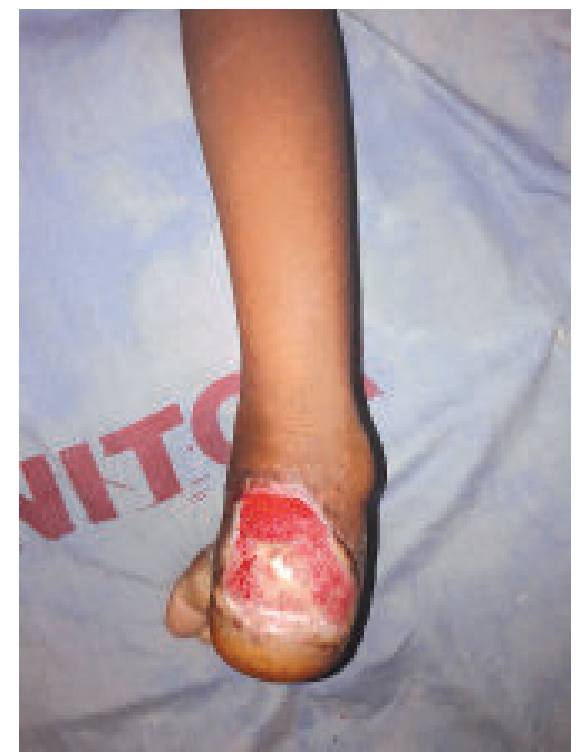

Fig.-1: Preoperative picture showing a post traumatic wound on posterior heel with exposed calcaneum.

Preoperatively age and sex of each patient, occupation, cause, size and site of the defect, time since injury, exposure of bone and tendons and presence of other injuries such as nerves, vessels were noted. Dimensions of the flap, level of the proximal flap margin when designed on the leg, island or paddled, capillary refill or congestion at the end of the procedure were recorded peroperatively. In the immediate postoperative period the flap was monitored for any venous congestion or pallor. Functional and aesthetic outcome was noted in terms of complete or partial flap survival, successful coverage of the recipient defect, difficulty in walking or problem in wearing shoes, ambulatory status of the injured limb after six months and any concerns of the patient regarding the aesthetic appearance of the flap. Donor site healing or any complication was also recorded. Pre and postoperative photograph of each patient were taken and surgical procedure was performed by one surgeon. Patients were discharged on the $8^{\text {th }}$ to $10^{\text {th }}$ postoperative day in case of uneventful recover and $15^{\text {th }}$ post operative day in case of extended sural flap. They were followed for at least 18 months.

\section{Surgical technique:}

After wound excision, the defect was measured with a mathematical ruler, the greatest length and the greatest breadth was recorded in centimeter. To outline the pedicle, a flap axis was drawn from midway between the lateral malleolus and Achilles tendon to the midline of the popliteal fossa. To locate the arc of rotation, a mark is made 5 to $7 \mathrm{~cm}$ proximal to the tip of the lateral malleolus, avoiding injury slightly distal septocutaneous perforators.

The skin island was marked along the axis of the sural nerve and lesser sephanous vein in the middle of the posterior aspect of the leg. This could be only in the proximal third of the leg or proximal and middle third depending on the size and site of the defect.

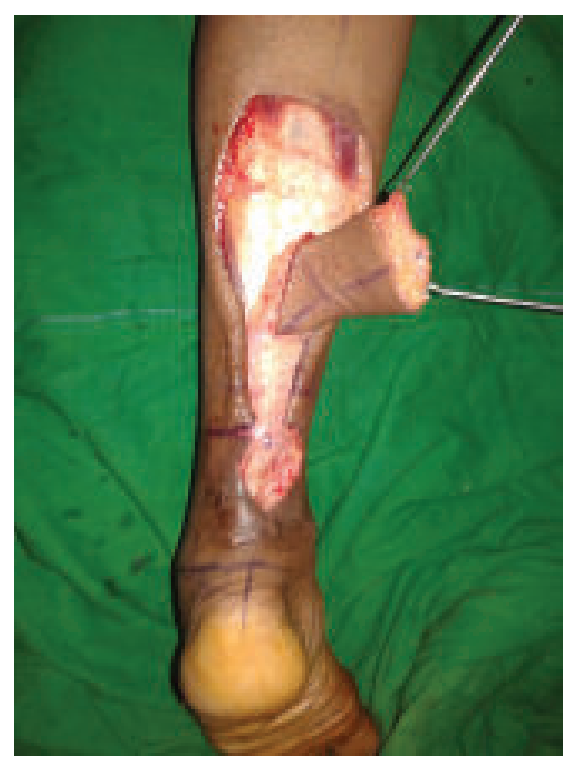

Fig.-2: Peroperative picture after flap elevation.

The dissection was started at the proximal border of the skin island. The sural nerve and artery and lesser sephanous vein were ligated 1 to $2 \mathrm{~cm}$ proximal to the proximal border of the skin paddle between the two heads of the gastrocnemius, at or close to the popliteal fossa. The sural nerve and artery are located deeper between two head of the gastrocnemius while lesser sephanous vein is always superficial. We extracted all the elements and tissues in the mesentery-like 
structures while keeping them connected to the flap and at the end, nothing remained between the two heads of the gastrocnemius. In wide flaps, lateral sural nerve, if present and it's accompanying artery were also included in the flap. Delayed procedure were applied for those flaps, which were harvested from the upper third of the back of the leg.

The skin was elevated along with the fascia. The fascia was sutured to the skin when elevated the flap from the muscles. The breadth of the pedicle was kept at least $3 \mathrm{~cm}$. Except in small flaps, we were not able to directly close the donor site and applied a skin graft.

\section{Results:}

Over the period of five years, a total of 50 distally based sural fasciocutaneous flaps were performed on 50 patients. All the patients were treated with initial resuscitation, wound excision, control of infection by giving antibiotic according to culture and sensitivity and regular dressing. After second or third look debridement, as indicated and control of infection definitive surgery was done to resurface the soft tissue defect.

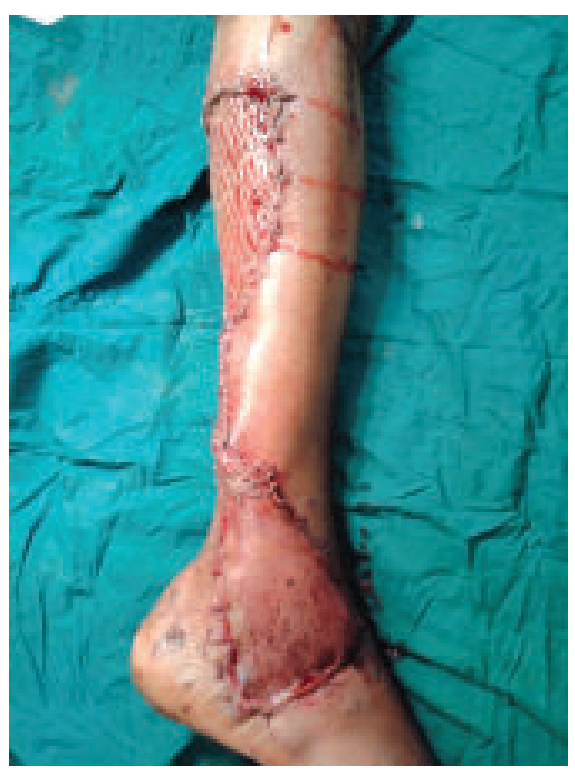

Fig.-3: The flap is used to cover lateral malleolus

The age varied from 7 to 55 years with the average of 31 years, 43 patients were male and 7 patients were female. $80 \%$ of the patients were in $25-55$ years age group indicating that the younger and earning members of the family are mostly involved in this sort of trauma. Road traffic accident was the cause of soft tissue defects in $35(70 \%)$ patients, other trauma such as handling of machineries in $5(10 \%)$ patients, fall from height and household trauma in 10(20\%) patients.

The site of the defect was exposed tendo Achilles in 30 patients, medial malleolus in 7 patients, lateral malleolus in 6 patients, exposed extensor tendons in 4 patients and three patients had more than one injuries.

Table-I

\begin{tabular}{|c|c|c|}
\hline \multicolumn{3}{|c|}{$\begin{array}{l}\text { Showing the distribution of soft tissue defects } \\
\text { around the ankle }\end{array}$} \\
\hline Location & Iumber of patients & percentage \\
\hline $\begin{array}{l}\text { Extensor tendons, . } \\
\text { nerves, vessels }\end{array}$ & 04 & $08 \%$ \\
\hline Medial malleolus & 07 & $14 \%$ \\
\hline Lateral malleolus & 06 & $12 \%$ \\
\hline Tendo Achilles & 30 & $60 \%$ \\
\hline More than one injuries & 03 & $06 \%$ \\
\hline
\end{tabular}

The dimension of the flap ranged from $6 \times 4 \mathrm{~cm}$ to 20 $\mathrm{x} 10 \mathrm{~cm}$. Mean length was $10.2 \mathrm{~cm}$ and mean width 7.1 cm. 38 (74\%) flaps were islanded and 12(24\%) flaps were harvested with skin paddle. The flaps to cover exposed Achilles tendon, malleolus were designed within lower two third. The remaining flaps were designed higher in the proximal third of the leg and gastrocnemius cuff was included in the upper part of the flap. The pivot point was kept was kept 6-7 cm proximal to the lateral malleolus in all cases.

Out of 50 patients, 36 flaps were completely survived, marginal flap necrosis in 5 patients, partial flap necrosis in 8 patients and complete flap loss in 1 patients. 2 patients developed hematoma managed by evacuation. One patient developed seroma and 5 patients developed wound infection on $6^{\text {th }}$ POD treated by drainage and antibiotic according to $\mathrm{c} / \mathrm{s}$. In all patients with complete survival of the flap and those with marginal necrosis( the necrosis area was debrided, flap advanced and resutured to the defect margin) successful coverage of the defects were achieved. 2 patients had partial flap loss managed by wound debridement and STSG and 1 patients had total flap loss which was managed by other reconstructive options. 


\section{Table-II}

Showing outcome of Flap

Outcome

Number of patients

\begin{tabular}{ll}
\hline Completely survived & 35 \\
Marginal necrosis of a maximum of 2 mm of flap margin & 05 \\
Marginal/Partial flap necrosis amenable to secondary advancement repair & 08 \\
Total flap loss & 02 \\
\hline
\end{tabular}

All patients were followed up to 18 months to see functional and aesthetic outcome. Range of ankle movement reduced in all cases. Out of 40 patients 20 patients had flap thickness 1-2mm, 7 patients had flap thickness about $3-5 \mathrm{~mm}$ and 13 patients had more than $5 \mathrm{~mm}$. More than $50 \%$ of patients had poor color match compared to the normal limb.

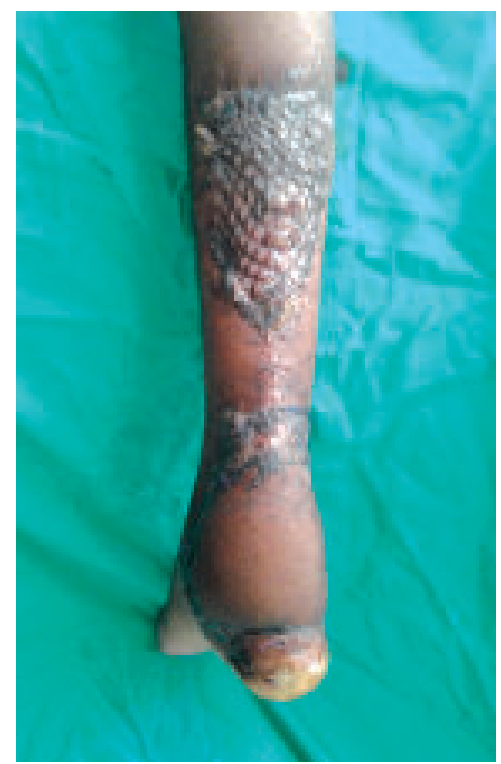

Fig.-4: Post operative picture after 1 month

\section{Discussion:}

Soft tissue reconstruction around the lower third of the leg and foot poses a considerable challenge to the reconstructive surgeon because of the composite tissue defects, inadequate and tight local tissues and poor circulation. ${ }^{6}$ Tendons , bone or hardware are frequently exposed because of the thinness of subcutaneous tissues. Following development of flap surgery, pedicled fasciocutaneous flap and free flap have been used. The introduction of distally based sural fasciocutaneous flap provides reliable and effective method to cover skin defects of distal leg, foot and ankle.

Various techniques have been adopted to increase the blood flow and hence the survival of the flap. These are : keeping the pedicle at least $4 \mathrm{~cm}$ wide, including gastrocnemius muscle cuff specially when the flap is designed higher in the leg and sural flap delay procedure specially when the large flaps are planned.

In most cases, the sural nerve descends in between the two heads of the gastrocnemius muscle and penetrate the deep fascia at the median point of the leg. In a smaller percentage of cases, it remains hidden inside the muscle along most of its path. ${ }^{7,8}$ The superficial sural artery originates from the popliteal or sural arteries and reaches the sural nerve at 2 to $3 \mathrm{~cm}$ after it's emergence, then subdivides into the medial, median and lateral superficial sural arteries. The median superficial sural artery follows the course of the sural nerve, then emits numerous branches toward the skin at the lower half of the leg along its subfascial path. There are few perforators at the upper half of the leg. In 65 percent of cases, it is reduced to an interwoven vascular network in the distal third of the leg. ${ }^{8}$ In both cases, there are anastomoses with the peroneal artery, through 3 to 5 septocutaneous perforators, which would ensure irrigation of the reverse-flow flap. The peroneal artery, in turn, makes other anastomoses, notably through its descending, specially with the anterior tibial artery. These anastomoses have also be confirmed by the Torii et al, who also cites the collaterals for the posterior tibial artery, and come to the conclusion that reverse flow would occur in any arteryof the large size. ${ }^{9}$ Several authors sustain that the principal anastomoses occurs at above to $5 \mathrm{~cm}$ from the lateral malleolus. ${ }^{9,10,11}$ 
During harvesting the standard flaps sometimes dissection was extended to the proximal third of the calf to find the pedicle elements a few centimetre proximal to the skin paddle. here we saw tiny vessels around the sural artery and nerve, where they passing under the deep fascia between gastrocnemius heads and also around the lesser sephanous vein, which was always superficialto the fascia over the gastrocnemius heads. These miniature vessels lie in a fibro-adipoareolar tissue between the two heads of the gastrocnemius muscle make a mesentery like structure connected to the deep fascia. ${ }^{5}$

The result of the study shows that the majority of the patients recovered very well in term of functional and aesthetic outcome. Other patients develops minor complications such as marginal flap necrosis, partial flap loss, wound infections and $2 \%$ cases there was total flap necrosis. These findings are very much consistent with other studies.

In a study in Iran, they harvested medium to very large sized flaps from extended to the upper third of the calf in 28 patients to cover the defects in distal tibia, ankle, heel, foot and sole. Their result showed that majority of the flap resulted in a good coverage of the defects 5 . Only distal $1 \mathrm{~cm}$ of a large flap developed marginal necrosis in the distal border which was treated by secondary skin graft. In a review and case series by Ahmed et al in 2008 where they utilized reverse flow sural neurocutaneous flap to cover the vital structures around the foot and ankle area where maximum size harvested was $14 \mathrm{~cm}$, here was no flap failure, venous congestion was encountered in one case but the donor site was relatively unsightly but acceptable to all patients foot and ankle ${ }^{2}$. Another study conducted in Pakistan in 2009 where they performed distally based sural fasciocutaneous flap for soft tissue reconstruction of the distal leg, ankle, foot defects ${ }^{3}$. Out of 25 flaps 20 showed complete survival (80\%), partial flap loss was found in 2 patients( $8 \%$ ),marginal flap necrosis in two patients(8\%) and complete flap loss in one patient.

Jeng SF et al used this technique to cover exposed Achilles tendons and soft tissue defects of the ankle and the heel. Of the 22 patients, 20 had complete success with two minor complications that were treated uneventfully ${ }^{11}$ but in another study they used this flap on 15 patients for soft tissue coverage of the lower leg, malleolar and heel margins. Twelve flap survived, two partially survived and one flap failed due to persistent infection ${ }^{12}$. Jeng et al. reported their experience with the use of the distally based sural artery flap for salvage of the distal foot. In seven out of eight patients, the flaps survived completely and only one patient had partial necrosis of the flap ${ }^{12}$. Similar type of study was done in Pakistan on 2007 where they treated 11 patients with soft tissue defect of the lower one third of the foot. All flaps except one survived. Most flap showed slight venous congestion which cleared in a few days. There was no loss of split skin graft $^{6}$.

The study done in Bangladesh by Kalam et al treated 30 patients with exposed tendo Achilles with superficial sural island flap with excellent outcome ${ }^{8}$. The flap survived in 26 cases without any sort of complication. But in our study we harvested medium to large sized flaps from upper third of the calf in 13 patients to cover the defects in medial, lateral malleolus and aterior surface of the ankle.only 2 patients developed marginal necrosis.(the necrosed areas were debrided, flap advanced and resutured to the defect ${ }^{8}$.

Irrespective of etiology coverage of exposed soft tissue done is mandatory and essential for prevention of complications. Our clinical study recommends distally based sural artery flap as a good choice to cover soft tissue defects around the ankle because the flap has numerous advantages. It is one stage operation. Elevation of the flap is easy and quick with minimum donor site morbidity. The vascular supply to the arterial network of the sural area is constant and reliable. Thus the distally based sural artery flap can be used as a good alternative to microsurgical reconstruction.

\section{Conclusion:}

The distally based sural flap is a versatile flap for coverage of soft tissue defects around the ankle. The procedure is done as a single stage with short operating time and minimum morbidity. Thus the superficial sural artery flap can be used as a good alternative to microsurgical reconstruction.

\section{Reference:}

1. Ebrahimi A, Nejadsarvari N, Kaushki ES. Experience with reverse flow sural flap to cover defects of the lower legs and foot, Trauma monthly 2011; 16(4): 178-181. 
2. Ahmed S. K, Fung BKK, Ip WY, Fok M, Chow SP. The versatile reverse flow sural artery neurocutaneous flap: A case series and review of literature, Journal of Orthopedic surgery and research 2008; 3(1): 15-20.

3. Ajmal S, Khan MA, Khan RA, Shadman M, Yousuf K, Iqbal T. Distally based Sural fasciocutaneous flap for soft tissue reconstruction of the distal leg, ankle and foot defects, Journal of Ayub Medical College Abbottabad 2009: 21(4): 19-24.

4. Ip KC, Lee KB, Shen WY. The use of a reverse flow Sural fasciocutaneous flap in a patient with multiple trauma: a case report, Journal of Orthopedic surgery 2008; 16(3): 373-377.

5. Hassenpour SE, Khan M, Arasleh E. Is it safe to extract the reverse sural artery flap from the proximal third of the leg? Archives of Iranian Medicine 2008; 11(2): 179-185.

6. Pirwani MA, SamoSaeed, Soomro YH. Distally based Sural Artery flap: A workhorse to cover the soft tissue defects of lower 1/3 tibia and foot, Pakistan Journal of medical science, January-March 2007; 23(1): 103-107.

7. Almeida MF, Costa PR Da, Okawa RY, , Reverse flow Sural island flap, Plastic and Reconstructive Surgery 2002; 109: 583-591.

8. Kalam MA, Faruquee SR, Karmakar SK, Khadka PB. Superficial Sural artery island flap for management of exposed Achilles tendon- surgical technique and clinical results, Kathmandu University Medical Journal 2005; 3(12): 401-410.

9. Fraccalvieri M, Verna G, Dolect M, Fava AM, Rivarossa A. Distally based superficial sural flap : our experience in reconstructing lower leg and foot. Annual Plastic surgery 2000; 45(2):132-140.

10. $\mathrm{Xu} \mathrm{G}$, Jin LL. The coverage of skin defects over the foot and ankle using the distally based sural neurocutaneous flaps: Experience of 21 cases. J Plast Reconstr Aesthet Surg 2008; 61: 575-577.

11. Jeng SF, Wei FC. Distally based sural island flap for foot and ankle reconstruction. Plast Reconstr Surg 1997; 99: 744-750.

12. Jeng SF, Wei FC, Kuo YR Salvage of the distally foot using the distally based sural island flap. Ann Plast Surg 1999; 43: 499-505.

13. Torii S, Namiki Y, and Mori R, Reverse- flow island flap: Clinical report and venous drainage. Plast. Reconstr. Surg. 1987;79: 600-605.

14. Masquelet A. C., Romana M. C. and Wolf G. skin island flaps supplied by the vascular axis of the sensitive superficial nerves: Anatomic study and clinical experience in the leg. Plast. reconstr. surg. 1992;89: 1115-1120.

15. Hasegawa, M. The distally based superficial sural artery flap. Plast. Reconstr. Surg. 1994;93: 1012-1018. 